\title{
Auction Mechanism and Methods for Heterogeneous Goods Such as Multiple Polymer Materials
}

\author{
Congjun Rao \\ College of Mathematics and Computer Science, Huanggang Normal University, \\ Huanggang 438000, China \\ cjrao@163.com
}

Keywords: Multi-object auction; heterogeneous goods auction; Polymer Materials

\begin{abstract}
Multi-object auctions can be divided into homogeneous goods auction and heterogeneous goods auction. In this paper, the auction mechanism and methods for heterogeneous goods such as multiple polymer materials (rubber, plastic, polymer fibre, adhesive, polymer coating) is investigated. Concretely, the research history and the newest research trends are introduced, and many widespread theoretical and applied problems are presented. In addition, assumptions, main ideas, and conclusions of literature related to heterogeneous goods auction are commented and reviewed.
\end{abstract}

\section{Introduction}

In the market trade, the buyers often encounter high polymer materials procurement, such as the rubber, plastic, polymer fibre, adhesive, polymer coating and polymer matrix composites. We can use the auction method to procure this kind of polymer materials. This kind of auction belongs to heterogeneous goods auctions. Heterogeneous goods auctions are more complex than the homogeneous goods auctions, one of the significant difference between heterogeneous goods auctions and homogeneous goods auctions is the super-additivity or sub-additivity of the buyer's preference for multiple combinations goods. In other words, when estimating the valuation of a number of different goods, the valuation of the combination of multiple goods generally is not equal to the sum of every single good valuation. In fact, the valuation of multiple goods related to two kinds of relationships of goods, i.e., complementary relationship and alternative relationship.

\section{Auctions of Heterogeneous Complementary Goods and Alternative Goods}

For multiple complementary heterogeneous goods auction, Palfrey [1] studied a monopoly's strategy selection problem of selling the heterogeneous goods between the bundling sales type and separate sales type, and pointed out that the seller's enthusiasm of bundling sales type will increase with the decrease of the number of bidders. Levin[2] researched the problem of auctioning complementary heterogeneous goods, and gave an optimal auction mechanism. Based on this study, Avery and Hendersoott [3] also studied the optimal auction for heterogeneous goods with a complementary relationship. They pointed out that in the optimal mechanism, enhancing the competition of one good will impact on the sale of another good, the consequences of this effect may make the selling price of other goods increased, but also may reduce.

In addition, aiming at the difficult problems of calculation in an auction of multiple heterogeneous combination complementary goods, Hsieh [4] proposed a heuristic algorithm to determine the winning bidder, and analyzed the information optimization problem of the simultaneous combinatorial auctions and multi-round combinatorial auction approaches. Andersson and wilenius [5] analyzed and compared the efficiency between the simultaneous auctions and combinatorial auctions, and showed that the expected income under the first price sealed combinatorial auction is higher than the simultaneous auction, and first proved that the combinatorial auctions can produce high incomes in theory, which is an important conclusion of multi-objects auction. 
Maskin and Riley generalized Myerson's optimal auction mechanism to multi-goods, but the generalized optimal mechanism is not applicable to the auctions of complementary or alternative heterogeneous goods. Palfrey [1] studied multiple complementary heterogeneous goods auction, but he only analyzed the seller's preference relation choice between bundling sales type and separate sales type, and the change of the numbers of buyer impact on the auction efficiency of bundling sales type, and did not put forward a reasonable and feasible heterogeneous goods auction mechanism. Although Levin and Avery studied the optimal auctions of complementary goods, they only considered the special case that buyers' valuation distribution is symmetric. Since then, the research progress on optimal auctions of heterogeneous complementary goods is very slow.

The auction of heterogeneous alternative goods is another important part of the multi-object auctions. Milgrom and Weber [6] studied and compared the efficiency of the sequential auction mechanism for a variety of heterogeneous alternative goods with some general assumptions, and showed that due to the impact of the "winners curse", the buyer has the post-purchase intention, which becomes the theoretical basis for a conclusion as to the interpretation and understanding the phenomenon in the Internet auction.

Kannan [7] pointed out that in a sequential-auction setting, the expected-winning prices are shown to decline across two stages when all bids are revealed between the stages. The prices decline because bidders desire to hide their private valuation information. The hiding also leads to inefficient allocations. Pitchik [8] studied a budget-constrained, private-valuation, sealed-bid sequential auction with two incompletely-informed, risk-neutral bidders in which the valuations and income may be non-monotonic functions of a bidder's type. Parameters permit the existence of multiple equilibrium symmetric bidding functions that differ in allocation, efficiency and revenue. He showed that the sequence of sale affects the competition for a good and therefore also affects revenue and the prices of each good in a systematic way that depends on the relationship among the valuations and incomes of bidders. Said [9] analyzed a dynamic market in which buyers compete in a sequence of private-value auctions for differentiated goods. New buyers and new objects may arrive at random times. Since objects are imperfect substitutes, buyers' values are not persistent. Instead, each buyer's private value for a new object is a new independent draw from the same distribution. We consider the use of second-price auctions for selling these objects, and show that there exists a unique symmetric Markov equilibrium in this market. In equilibrium, buyers shade their bids down by their continuation value, which is the (endogenous) option value of participating in future auctions. He characterizes this option value and showed that it depends not only on the number of buyers currently present on the market and the distribution of their values, but also on anticipated market dynamics. Further, Bapna et al. [10] studied settings where a number of sellers simultaneously offer vertically differentiated Vickrey auctions for imperfect substitute goods to unit-demand buyers. Vertical differentiation can arise from differences in item quality, item value certainty, seller reliability, or a combination of these factors. They characterized the form of the bidding equilibria and derived expressions for the corresponding allocative efficiency and expected seller revenue.

The above studies found that most of the studies focus on a different auction in the income comparison, the theoretical literature on the economic efficiency of the multi-objects auction is relatively few. The theoretical and experimental studies have shown that: do not consider the premise of the buyer collusion, the auction is efficient [98-99]. Moreover, revenue maximization and efficiency are closely related. Under some special assumptions (such as the buyer's valuation obey the binomial distribution), the optimal auction is efficient. Under normal circumstances, maximize the return and effectiveness are not compatible. For this reason, on the mechanism design of multi-objects auction, future studies need to focus on both buyers and sellers' benefits maximization and high-efficiency to design the optimal auction mechanism for the homogeneous goods and the heterogeneous goods. 


\section{Empirical Studies of the Multi-object Auctions}

On empirical study of multi-object auction, Bower and Bunn [11] used agent-based computational economics approach (ACE) to design experiments in the context of electricity pricing in the electricity market in England and Wales, and showed that the electricity price generated by the uniform price auction is lower than the discriminatory price auction. Abbink et al. [12] studied the practical problems of government bond auction with fixed supply and the buyer has a total valuation model under the premise of the two units of demand, and designed a experiment to show that the government revenues generated by the uniform price auction is higher than the discriminatory price auction. Sade [13] proposed a new experimental method to test the performance of three different multi-object auctions: discriminatory price auction, uniform price auction with fixed supply and the uniform price auction with variable supply. The experiments concluded that the practical strategies do not match the balanced strategies proved theoretically, and the discriminatory price auction is more likely to cause the occurrence of tacit collusion than any form of uniform price auction. Zhang [14] used the experimental methods to compare the income differences between the uniform price auction mechanism and the fixed issue mechanism of stock initial Public Offering (IPO). The results show that the uniform price auction mechanism is better than the fixed issue mechanism. Damianov [15] designed the auction experiments to verify some valuable conclusions based on his own relevant conclusions, i.e., in the multi-object auction with variable supply and buyers with unit demand, the uniform price auction can generate higher expected return and higher auction efficiency than the discriminatory price auction. These empirical studies can not easily draw general conclusions directly from experiment, and the experimental design is only to verify the conclusions of the existing theoretical research, and amended the unreasonable conclusions. In the real auction, the bidding decision-making process of many auctions is very complex, and sometimes is difficult to describe with the mathematical model. Then the experiment method can simulate the auction process and discover the new problems for theoretical research direction.

For the multi-object auction, compared with overseas research, our country paid more attention to the auctions' modeling and calculation optimization of laws, business, procedures and clearing price. Moreover, the theoretical studies on the mechanism have some results, but whether it is in the depth, breadth, there is a certain gap, which limits our common economic means, especially in-depth understanding and application of online multi-object auction.

There are also some domestic related studies on multi-object auction, for example, Xu focused on the performance of the auction mechanism and the optimal auction mechanism design problem, and gave a systematic introduction to the main developments in the theory of the international auction for nearly half a century. Ma and Wang gave a comprehensive introduction and summary to concept, theory, applications, trends and problems of the auction and online auction. Chen etc. analyzed and summarized the research progress of the traditional single goods, multi-object auction and online auctions, and gives a number of cutting-edge research questions. Shu studied commence many topics on the auction and online auction, such as an overview of the origin of the auction, the definition of the way, features, and so on, and discussed the Treasury auction selection mode theory, and gave the comparison on the auction market in the United States, Britain and China.

In addition, there are also a small number of scholars studied the buyer's strategic behavior from the perspective of the buyer. Xiong studied the bidding strategy of the buyer on the auction price within the analytical framework in the uniform price share auction bidding strategies and auction underpricing relational model and gave a new class of linear equilibrium bidding function. Based on this uniform price share auction, subsequently, Zhou deduced the equilibrium when IPO issue price and net IPO underpricing expression sellers maximize expected return for the case of institutional investors in the IPO prior to purchase total to determine the optimal bidding price. Long summarized buyer's bidding behavior and equilibrium outcomes of several common auctions under different assumptions and limitations. 
At present, the domestic research on auction is more and more colorful, but mainly to the interpretation and application of foreign auction theory, focusing on the economic formula in the field of interpretation and analysis instructions. In particular, the mechanism design and application of homogeneous divisible goods are deficient.

\section{Theoretical Questions and Comments on Multi-Object Auction}

After 50 years of development, multi-object auction theory has a more mature theoretical framework, its application areas are more and more widely. However, there are many hot topics and cutting-edge issues need further study and discussion.

Since Vickrey, scholars studied the multi-object auction mostly from the point of view of asymmetric information, and did not involve the discussion on the issues of competition between the auction mechanism and other marketing mechanisms. This starting point limits the development of the auction theory. The design of the existing auction mechanism for multiple goods generally assumes that the seller has full bargaining power, which reflects the characteristics of the auction.

However, the monopoly power of sellers is too much emphasis on auction theory into a blind pursuit of sellers' return maximization. Comprehensive analysis of the existing multi-object auction literatures, the auction mechanism based on the buyer's point of view is very inadequate, but also to analyze auction performance from other outside income measure standard is also extremely rare. Therefore, the explanatory power of the reality of the multi-object auction theory for auction practice is still relatively limited. From a more practical point of view to consider the multi-object auction mechanism design and evaluation of the performance of the auction mechanism are important direction for future research.

Tacit collusion between the buyers is one of the core problem need to be considered in the mechanism design of multi-object auctions. Whether design a optimal efficiency mechanism or design a optimal mechanism with return maximization, the tacit collusion between the buyers will affect the sellers' auction goals.

In the practice of multi-object auction design, if an auction mechanism can effectively reduce or prevent the buyer tacit collusion, it must rely on the basic characteristics of the physical environment of the auction market, auction items, buyers and sellers' goal and other factors. However, different auction market, auction goods, and the different types of buyer all have complex uncertainties, which makes more difficult to design specific auction rules. But whether it is speaking from theory or from a practice, to study the tacit collusion problem in multi-object auction has a very important theoretical and practical significance.

The information problem is a problem worthy of further study in the multi-object auction design. The level of information openness and information hiding will directly affect the bidding strategy of buyer and the seller and the buyers' incomes. However, the existing scholars are basically confined to the single good auction for the study of the information problem. The study on information superiority of correlation value between multi-objects is very few in existing studies. Therefore, to study information superiority (asymmetric) in the multi-object auction problem is an important frontier of auction theory, and has important theoretical significance and application value for the deepening and development of auction theory.

\section{Acknowledgments}

This work is supported by the 2012 National Natural Science Foundation of China Grant to C.J. Rao, and the 2012 Excellent Youth Project of Hubei Provincial Department of Education (No. Q20122702), and the Ph.D. Fund of Huanggang Normal University to C.J. Rao, and the 2011 Project of Huanggang Normal University to C.J. Rao(NO.2011cb087). 


\section{References}

[1] T. R. Palfrey, Bundling decisions by a multi-product monopolist with incomplete information, Econometrica 51 (1983) 463-484.

[2] J. Levin, An optimal auction for complements. Game and Economic Behavior 18 (1997) 176-192.

[3] C. Avery and T. Hendershott, Bundling and optimal auctions of multiple products, Review of Economic Studies 67 (2000) 483-497.

[4] F. S. Hsieh, Combinatorial reverse auction based on revelation of Lagrangian multipliers, Decision Support Systems 48 (2010) 323-330.

[5] A. Andersson and J. Wilenius, A new analysis of revenue in the combinatorial and simultaneous auction, Working Paper, 2009.

[6] P. Milgrom, R. Weber, A theory of auctions and competitive bidding, Econometrica 50 (1982) 1089-1122.

[7] K. N. Kannan, Declining prices in sequential auctions with complete revelation of bids, Economics Letters 108 (2010) 49-51.

[8] C. Pitchik, Budget-constrained sequential auctions with incomplete information, Games and Economic Behavior 66 (2009) 928-949.

[9] M. Said, Sequential auctions with randomly arriving buyers, Games and Economic Behavior, (2011), in press.

[10] R. Bapna, C. Dellarocas and S. Rice, Vertically differentiated simultaneous Vickrey auctions: theory and experimental evidence, Management Science 56 (2010) 1074-1092.

[11]J. Bower and D. Bunn, Experimental analysis of the efficiency of uniform-price versus discriminatory auctions in the England and Wales electricity market, Journal of Economic Dynamics \& Control 25 (2001) 561-592.

[12]K. Abbink, J. Brandts and P. Pezanis-Christou, Auctions for government securities: a laboratory comparison of uniform, discriminatory and Spanish designs, Journal of Economic Behavior \& Organization 61 (2006) 284-303.

[13] O. Sade, C. Schnitzlein and J. Zender, Competition and cooperation in divisible good auctions: an experimental examination, Review of Financial Studies 19 (2006) 195-235.

[14] P. Zhang, Uniform price auctions and fixed price offerings in IPOs: an experimental comparison, Experimental Economics 12 (2009) 202-219.

[15] D. S. Damianov, J. Oechssler and J. G. Becker, Uniform vs. discriminatory auctions with variable supply-experimental evidence, Games and Economic Behavior 68 (2010) 60-76. 